\title{
Paleoecology grand challenge
}

\author{
Franco Biondi * \\ DendroLab, Graduate Program of Ecology, Evolution and Conservation Biology, University of Nevada, Reno, NV, USA \\ ${ }^{*}$ Correspondence: fbiondi@unr.edu \\ Edited by: \\ Mark A. Elgar, University of Melbourne, Australia \\ Reviewed by: \\ Michal Kowalewski, University of Florida, USA
}

Keywords: paleoecology, retrospective studies, proxy interpretations, paleoscience, paleoclimatology

Exactly 50 years ago, in 1964, a landmark article whose two-word title, "Strong inference," revealed little and evoked plenty, appeared in the hallowed pages of Science (Platt, 1964). Simply stated, Platt's view of scientific research in its highest form proceeds through three steps: development of alternative hypotheses; design of crucial experiments to exclude one or more hypotheses; execution of careful studies to obtain clear-cut results. It was a powerful reminder of how problem solving can be performed, written in a style both informal and authoritative. In those days it was not unusual for the most prestigious scientific outlets to publish articles whose language seems to nowadays have been relegated to blog posts. Just seven years earlier, another Science paper had appeared with a whimsical title, "Biological clock in the unicorn" (Cole, 1957), addressing the excessive reliance on statistical analysis of cycles and correlations that was plaguing the biologists of the time. Among the many citable passages in either one of those articles, one may dwell on a segment in Platt's text: "Whether it is hand-waving or number-waving or equation-waving, a theory is not a theory unless it can be disproved. That is, unless it can be falsified by some possible experimental outcome." Literal interpretations of such statements, especially when translated to all possible scientific research, are problematic, and Platt's impact is best described as "more an inspirational tract than the development of a formal scientific methodology" (Davis, 2006). It is in that vein that I decided to open this Grand Challenge editorial by evoking a paper from half a century earlier.

Paleoecology, as any other branch of retrospective science, does not easily lend itself to experimentation. Not because of any fault of its own, but simply because there is no experimental outcome capable of reversing the unidirectionality of time. Elsewhere (Biondi, 2013) I have explored the tension created by the imperative to understand ecosystem legacies and past environmental drivers against the impossibility of distinguishing between true and false when dealing with the past. As it turned out, I was partly rephrasing the meaning of "historicity," i.e., "the necessity of working with complex and unique events in time" (Gould, 1980). In the same vein, but even earlier, Nagel (1952) had discussed in detail the distinction and connections between the "nomothetic" aspects of science, "which seek to establish abstract general laws for indefinitely repeatable processes," and the "idiographic" ones, "which aim to understand the unique and nonrecurrent." These issues cut across the timescales used by Jackson (2001) to distinguish between "real time" (for modern ecology), "Qtime" (for Quaternary ecology), and "deep time" (for paleobiology and paleontology, which is the subject of another section of this journal).

Prescribing, even more than describing, the type of research that this journal section is aiming to attract and publish requires some epistemological considerations. Science is a method for reducing uncertainty (Lindley, 2006): thus, paleoecology could be considered a method for reducing uncertainty about past ecological patterns and processes. A subdivision into preliminary, exploratory, and confirmatory research has been proposed (Flueck and Brown, 1993), although the last term suggests an inherent bias, as even "validation" and "verification" are not truly possible when dealing with open systems (Oreskes et al., 1994). Choice of words notwithstanding, the most productive approach to science was demonstrated recently by the insightful views on exploratory vs. confirmatory research made by Wagenmakers et al. (2012) with regard to psychology_-another discipline where experimentation is rarely an option. What they define as confirmatory is in fact the type of rigorous scientific inquiry that begins with a priori definitions of expected outcomes. This practice is diametrically opposed to a posteriori analyses and rationalizations that are inevitably more influenced by investigator's bias. Their language is explicit, as in stating that "In fact, the advice to torture the data until they confess is not wrong-just as long as this torture is clearly acknowledged in the research report."

For clarity, I have found useful to categorize studies as (a) experimental, which are performed under controlled conditions in a laboratory or in the field with random assignment of treatments to subjects; (b) observational, when conditions are not entirely controlled or the assignment of treatments to subjects is not random; (c) iterative, whereby no treatments are possible, but a specific question is asked a priori and constantly refined by comparing predictions with outcomes (e.g., forecasting, opinion polls); (d) monitoring, when questions may not exist or are asked a posteriori (e.g., surveys, inventories, proxy reconstructions, data mining, remote sensing, cartography, automated recording). It is better to envisage these categories as part of a continuum rather than as discrete entities, so that at one end of the spectrum are experiments, and at the other end are observations designed to obtain descriptive measures of natural phenomena without including control units or manipulation of any 
sort. All research activities, including those labeled as "monitoring," can lead to scientific discoveries, as repeatedly shown in the atmospheric sciences (e.g., Keeling, 1960), forestry (e.g., Schreuder and Thomas, 1991), and epidemiology (e.g., Goldstein and Goldstein, 1984).

A large body of literature on what separates an experimental from an observational study can be found in the medical field. A typical example is the link between smoking and disease, which could not be established experimentally. In observational studies "the investigator is restricted to taking selected observations or measurements that seem appropriate for the objectives, either by gathering new data or using those already collected by someone else" (Cochran, 1983; p. 2). Cochran's book, which was published posthumously and mostly written before 1980 , is widely recognized as a classic reference. Estimates from an observational study are likely to be biased, not because of the investigator's shortcomings but because of potential differences in starting conditions, which make responses not comparable. Such confounding can easily mislead researchers, as shown by Simpson's paradox, whereby a medical treatment that is judged beneficial for all is also detrimental for both men and women (Lindley, 2006). A prominent role is therefore assigned to minimizing bias using three general methods: (1) refinement of techniques through devices, (2) blocking and matching, and (3) statistical adjustments (Cochran, 1983). Updated monographs on this topic (Rosenbaum, 2002, 2010) have emphasized that without treatments neither experimental nor observational studies can be performed. A list of procedures for improving research quality was provided by Rosenbaum (2010; pp. 57), but studies of past ecological changes are rarely able to meet these expectations.

In fact, all retrospective investigations fall in the "monitoring" category mentioned above because of the impossibility of either applying specific treatments, thus preventing experimental or observational investigations, or of using future outcomes to measure model skill, hence excluding an iterative approach. Although not necessarily a hierarchy for discovery potential, the study categories mentioned above are still in descending order for likelihood of raucous debate. As we transition from experiments to, for instance, proxy reconstructions of climate, there is a greater and greater chance that studies addressing the same questions but conducted by different investigators will provide conflicting results. Clever strategies have been proposed to circumvent and ameliorate some of these issues in an earth system science (ESS) modeling framework (e.g., Hughes and Ammann, 2009). On the other hand, any working scientist is well aware of the fact that results based on statistical correlations or simulation models, however complex they may be, are not necessarily harbingers of cause-effect relationships. In Fanelli (2010)'s words, "the nature of hypotheses tested and the logical and methodological rigor employed to test them vary systematically across disciplines and fields, depending on the complexity of the subject matter and possibly other factors (e.g., a field's level of historical and/or intellectual development)."

The purposely bare-bone taxonomy of scientific studies mentioned above has a biological perspective, but in a geophysics framework one would be confronted with the "forward" and "inverse" problem of linking data with underlying processes (Snieder and Trampert, 1999). A similar concept emerges when using a "statespace" approach, whereby "hidden" or "latent" variables are responsible for generating the observations (Harvey, 1990). Paleo reconstructions, and in general any proxy-record study, can be considered an inverse problem because incomplete information is used to infer the underlying parameters and processes (the "true" model) that generated them. However, it is an ill-posed inverse problem, because it has no unique solution, and small errors in the data cause large changes in the inferred explanation (King, 1997). The various assumptions made by the investigator to make sampling decisions, to account for measurement errors, to select theoretical probability distributions, to perform data reduction steps, etc. are needed to approximate a solution, but different approaches and options easily lead to diverging results (Biondi, 2014). The mission statement of the Paleoecology section outlines research topics that are pressing and essential in scope, but the major challenge for the field may be to remain well grounded in what can and cannot be accomplished. When investigating the past, and reporting research results, it is then appropriate to remind ourselves that we cannot prove hypotheses, and rather accept that some of them have not yet been proven false (Kinraide and Denison, 2003).

Another insightful argument was made by Cleland (2002) concerning scientific disciplines that attempt to predict the future and those that focus on postdiction of the past. The former proceed "from causes (test conditions) to effects, with the concomitant worries about ruling out false positives and false negatives," while the latter go "from effects (traces) to causes, with the concomitant worries about ruling out alternative explanations." A "predictive science" is therefore confronted with "the underdetermination of the future by the localized present," whereas a "postdictive science" deals with "the overdetermination of the past by the localized present." As argued by Pigliucci (2005), "the price for our ability to predict the future is that we can do so accurately only under very restrictive conditions," while accurate inferences about a past event can in some cases be derived using more than one type of empirical evidence. The main consequence of this asymmetry is that historical sciences tend to accumulate evidence in support of a hypothesis, rather than trying to disprove it.

Paleoecology cannot be segregated from the rest of ecological science (Rull, 2010), but its philosophical characterization as a postdictive field of study provides a useful frame of reference, particularly when confronted with the emphasis increasingly being placed on allencompassing simulations models (e.g., Anderson et al., 2006). A more effective approach was laid out in Harte's (2002) inspirational article on ESS: "There is, in ESS, a growing infatuation with ever more complex models. It's gotten to the point where some models look as inscrutable as nature itself. With numerous adjustable parameters, these models are generally unfalsifiable, so that the opportunity to learn from a wrong prediction is shortcircuited. A "Fermi approach" based on models that capture the essence of the problem, but not all the details, might get us farther. We need to develop simple, mechanistic models. They will, perforce, 
be caricatures of the Earth system, but they must be falsifiable." It may not be too farfetched to infer that Platt's approach reverberates in Harte's words, as well as in the prominence assigned to manipulation for distinguishing ecology from natural history (e.g., Ernest et al., 2009).

Science is a relatively young enterprise, as it emerged in its modern form at the time of Galileo, about 400 years ago. Even younger is the systematic study of uncertainty, which only dates back about a century (Lindley, 2006). These timeframes are miniscule compared to those during which humans have behaved as "political animals," using Aristotle's definition. To protect the infancy of scientific thought, especially given the nature of "postdictive" research, formal training in how to detect and reduce bias should be an essential component of graduate curricula in paleoecology, with the papers by Wunsch (2010) and Jackson (2012) among the required readings. With regard to this journal section, it is expected to value and attract studies of past ecological changes that foster analytical rigor and constant innovation, to provide an outlet where intellectual creativity and discovery-oriented efforts are wholeheartedly embraced, and to become an arena where vigorous debate on fundamental assumptions is allowed as long as it relies on evidence-based worldviews, thereby keeping in line with the principles that inspired Galileo's revolution.

\section{ACKNOWLEDGMENTS}

The author is grateful for the financial support received from a Charles Bullard Fellowship in Forest Research awarded by Harvard University to visit Harvard Forest in Petersham, Massachusetts. This material is based upon work supported by the US National Science Foundation under grants AGS-EAGER-1256603, P2C2-0823480, and BSC-1230329. The comments made by Michal Kowalewski helped improve an earlier version of the manuscript. The views and conclusions contained in this document are those of the author and should not be interpreted as representing the opinions or policies of the funding agencies.

\section{REFERENCES}

Anderson, N. J., Bugmann, H. K. M., Dearing, J. A., and Gaillard, M.-J. (2006). Linking palaeoenvironmental data and models to understand the past and to predict the future. Trends Ecol. Evol. 21, 696-704. doi: 10.1016/j.tree.2006.09.005

Biondi, F. (2013). The fourth dimension of interdisciplinary modeling. J. Contemp. Water Resour. Educ. 152, 42-48. doi: 10.1111/j.1936-704X.2013. 03166.x

Biondi, F. (2014). "Dendrochronology and volcanic eruptions," in Encyclopedia of Scientific Dating Methods, eds W. J. Rink and J. W. Thompson (Dordrecht: Springer Science+Business Media), 1-13.

Cleland, C. E. (2002). Methodological and epistemic differences between historical science and experimental science. Philos. Sci. 69, 474-496. doi: $10.1086 / 342455$

Cochran, W. G. (1983). Planning and Analysis of Observational Studies. New York, NY: John Wiley and Sons. doi: 10.1002/9780470316542

Cole, L. C. (1957). Biological clock in the unicorn. Science 125, 874-876. doi: 10.2307/ 1754178

Davis, R. H. (2006). Strong inference: rationale or inspiration? Perspect. Biol. Med. 49, 238-249. doi: 10.1353/pbm.2006.0022

Ernest, S. K. M., Valone, T. J., and Brown, J. H. (2009). Long-term monitoring and experimental manipulation of a Chihuahuan Desert ecosystem near Portal, Arizona, USA. Ecology 90, 1708. doi: 10.1890/08-1222.1

Fanelli, D. (2010). "Positive" results increase down the hierarchy of the sciences. PLoS ONE 5:e10068. doi: 10.1371/journal.pone.0010068

Flueck, J. A., and Brown, T. J. (1993). Criteria and methods for performing and evaluating solar-weather studies. J. Climate 6, 373-385. doi: 10.1175/1520-0442(1993)006<0373:camfpa > 2.0.co;2

Goldstein, M., and Goldstein, I. (1984). "Snow on cholera," in The Experience of Science: An Interdisciplinary Approach (New York, NY: Plenum Press), 29-71.

Gould, S. J. (1980). The promise of paleobiology as a nomothetic, evolutionary discipline. Paleobiology 6, 96-118. doi: 10.2307/2400239

Harte, J. (2002). Toward a synthesis of the Newtonian and Darwinian worldviews. Phys. Today 55, 29-34. doi: 10.1063/1.1522164

Harvey, A. C. (1990). Forecasting, Structural Time Series Models and the Kalman Filter. Cambridge: Cambridge University Press. doi: 10.1017/CBO97 81107049994

Hughes, M. K., and Ammann, C. M. (2009). The future of the past-an earth system framework for high resolution paleoclimatology: editorial essay. Clim. Change 94, 247-259. doi: 10.1007/s10584009-9588-0

Jackson, S. T. (2001). Integrating ecological dynamics across timescales: real-time, Q-time, and deeptime. Palaios 16, 1-2. doi: 10.1669/0883-1351 (2001) $016<0001$ :iedatr $>2.0 . c 0 ; 2$

Jackson, S. T. (2012). Representation of flora and vegetation in Quaternary fossil assemblages: known and unknown knowns and unknowns. Quaternary Sci. Rev. 49, 1-15. doi: 10.1016/j.quascirev.2012. 05.020

Keeling, C. D. (1960). The concentration and isotopic abundances of carbon dioxide in the atmosphere. Tellus 12, 200-203. doi: 10.1111/j.2153-3490.1960.tb01300.x

King, G. (1997). A Solution to the Ecological Inference Problem: Reconstructing Individual Behavior from Aggregate Data. Princeton, NJ: Princeton University Press.

Kinraide, T. B., and Denison, R. F. (2003). Strong inference: the way of science. Am. Biol. Teach. 65, 419-424. doi: 10.1662/0002-7685(2003)065[0419: sitwos]2.0.co;2

Lindley, D. V. (2006). Understanding Uncertainty. Hoboken, NJ: John Wiley and Sons, Inc. doi: 10.1002/0470055480

Nagel, E. (1952). Some issues in the logic of historical analysis. The Sci. Monthly 74, 162-169. doi: $10.2307 / 20798$

Oreskes, N., Shrader-Frechette, K., and Belitz, K. (1994). Verification, validation, and confirmation of numerical models in the earth sciences. Science 263, 641-646. doi: 10.1126/science.263. 5147.641

Pigliucci, M. (2005). Are the historical sciences sciences? Skeptical Inquirer 29, 20-21.

Platt, J. R. (1964). Strong inference. Science 146, 347-353. doi: 10.1126/science.146.3642.347

Rosenbaum, P. R. (2002). Observational Studies. New York, NY: Springer. doi: 10.1007/978-1-47573692-2

Rosenbaum, P. R. (2010). Design of Observational Studies. New York, NY: Springer Science+Business Media. doi: 10.1007/978-1-4419-1213-8

Rull, V. (2010). Ecology and palaeoecology: Two approaches, one objective. The Open Ecol. J 3, 1-5. doi: 10.2174/1874213001003020001

Schreuder, H. T., and Thomas, C. E. (1991). Establishing cause-effect relationships using forest survey data. Forest Sci. 37, 1497-1512.

Snieder, R., and Trampert, J. (1999). "Inverse problems in geophysics," in Wavefield Inversion, ed A. Wirgin (New York, NY: Springer-Verlag), 119-190.

Wagenmakers, E.-J., Wetzels, R., Borsboom, D., Van Der Maas, H. L. J., and Kievit, R. A. (2012). An agenda for purely confirmatory research. Perspect. Psychol. Sci. 7, 632-638. doi: 10.1177/174569161 2463078

Wunsch, C. (2010). Towards understanding the Paleocean. Quaternary Sci. Rev. 29, 1960-1967. doi: 10.1016/j.quascirev.2010.05.020

Conflict of Interest Statement: The author declares that the research was conducted in the absence of any commercial or financial relationships that could be construed as a potential conflict of interest.

Received: 21 May 2014; accepted: 04 August 2014; published online: 20 August 2014.

Citation: Biondi F (2014) Paleoecology grand challenge. Front. Ecol. Evol. 2:50. doi: 10.3389/fevo.2014.00050

This article was submitted to Paleoecology, a section of the journal Frontiers in Ecology and Evolution.

Copyright (c) 2014 Biondi. This is an open-access article distributed under the terms of the Creative Commons Attribution License (CC BY). The use, distribution or reproduction in other forums is permitted, provided the original author(s) or licensor are credited and that the original publication in this journal is cited, in accordance with accepted academic practice. No use, distribution or reproduction is permitted which does not comply with these terms. 